\title{
APPEARENCE OF GIANT PEROXISOMES IN MOUSE HEPATOGYTES TREATED WITH A HYPOLIPIDEMIG DRUG, SIMFIBRATE
}

\author{
KeI-IGHi HIRAI* and KazUo OGAWA** \\ Department of Cytochemistry*, Chest Disease Research Institute, Kyoto University, \\ Kyoto 606, and Department of Anatomy**, Kansai Medical School, \\ Moriguchi, Osaka 570
}

Received for publication July 20, 1973

\begin{abstract}
An enlargement as well as a remarkable increase in number of peroxisomes was electron microscopically encountered in mouse hepatocytes treated for 7 days with 1,3-propyl-bis (2-p-chlorophenoxy-2-methylpropanoate) (simfibrate, BCPMP), a hypolipidemic drug, that lowers serum chloesterol and triglycerids. Increase in number of peroxisomes was approximately 3 times of that in control cells. The general size of enlarged peroxisomes was $1.33 \times 1.07 \mu$, and approximately 2.5 times as compared with normal peroxisomes, $0.54 \times 0.46 \mu$, in control hepatocytes.

The use of the term "giant peroxisomes(megaloperoxisomes)" is proposed in the present investigation.

Giant peroxisomes had protein-riched matrix surrounded by a single membrane, and many of them contained a single nucleoid. Continuities or close associations between giant peroxisomes and the smooth or rough endoplasmic reticulum were frequently observed. Further detailed investigations on the origin of giant peroxisomes and relationship to pharmacological effect of BCPMP will be achieved.
\end{abstract}

During the course of the ultracytochemical studies of the hepatocytes in the mouse treated with 1,3-propyl-bis (2-p-chlorophenoxy-2-methylpropanoate) (simfibrate, BCPMP), a hypolipidemic drug, which lowers serum cholesterol and triglycerides $(10,11)$, we have encountered with a remarkable increase in number as well as an enlargement of peroxisomes.

It has been known that ethyl- $\alpha$-p-chlorophenoxyisobutyrate (CPIB), possessing similar pharmacological effects to BCPMP, stimulates a significant increase in number of peroxisomes and in the rate of catalase synthesis in male rat liver $(6,17$, $20,21)$ and in normal male mouse liver $(19,23)$, that peroxisome proliferation is dependent on sex hormones in normal rats (22) but independent in acatalasemic mice $(15,16,18)$ treated with CPIB, and that the number of peroxisomes increases in the absence of significant catalase synthesis (17). However, an enlargement of individual peroxisome has never been precisely described thus far.

The present report deals with morphological changes observed in mouse hepatoperoxisomes treated with BCPMP, and furthermore the use of the term "giant peroxisomes (megaloperoxisomes)" is proposed to the abbormally enlarged peroxisomes. 


\section{MATERIALS AND METHODS}

Ten male adult DD mice, weighing approximately $20 \mathrm{~g}$, were given intraperitoneally BCPMP (Yoshitomi Pharmaceutical Industries, Ltd., Osaka) suspended in $0.5 \%$ methyl cellulose solution in a daily dose of $1,000 \mathrm{mg} / \mathrm{kg}$ body weight, for 7 days. Other 9 mice administered methyl cellulose alone by the same way were used as control. On the eighth days, the animals were sacrificed by cutting of the carotid arteries. Livers were fixed for $1 \mathrm{hr}$ in ice-cold $2.5 \%$ osmium tetroxide in $0.1 \mathrm{M}$ phosphate buffer at $\mathrm{pH}$ 7.4. Some pieces of livers were fixed for $2 \mathrm{hr}$ in $2.5 \%$ glutaraldehyde buffered with $0.1 \mathrm{M}$ cacodylate at $\mathrm{pH}$ 7.4. For cytochemical examination, glutaraldehyde-fixed frozen sections cut at $50 \mu$ thick were incubated for 60 min either in a $\mathrm{pH}$ 9-DAB medium containing $10 \mathrm{mg}$ 3,3'-diaminobenzidine tetrahydrochloride (E. Merck) and $2 \mu \mathrm{l}$ of $30 \% \mathrm{H}_{2} \mathrm{O}_{2}$ in $10 \mathrm{ml}$ of $0.05 \mathrm{M}$ 2-amino2-methyl-1,3-propandiol buffer (12), or in a $\mathrm{pH}$ 7.2-DAB medium buffered with $0.1 \mathrm{M}$ Tris-HCl after treatment for $1 \mathrm{hr}$ in $0.2 \mathrm{M}$ formamide (7). Cytochemically incubated sections were rinsed thoroughly in $0.1 \mathrm{M}$ phosphate buffer, $\mathrm{pH} 7.4$, and osmicated for $1 \mathrm{hr}$ in phosphate buffered cold $1 \%$ osmium tetroxide, followed by ethanol dehydration and embedding in Epon 812. Thin sections were made on an LKB ultrotome and examined with a JEM-7A electron microscope operated at 80 $\mathrm{KV}$.

The statistical measurements in size and number of peroxisomes were provided from 32 random micrographs obtained from 3 experimental mouse livers, and from 32 micrographs of 3 controls. Peroxisome conformations in which limiting membranes were hazy caused by a detached section from the central portion, indicating inaccurate size in diameter of the particles, were omitted from the size-measurement.

\section{RESULTS}

\section{Control liver}

Peroxisomes in control DD mouse hepatocytes were scattered at random in the cytoplasm, and the typical shape of the mature particles was nearly round at approximately $0.5 \mu$ in diameter with variation from 0.3 to $0.9 \mu$ surrounded by a

TABLE 1 Size-distribution in peroxisomes*

\begin{tabular}{l|c|c}
\hline \multicolumn{1}{c|}{ Group } & $\begin{array}{c}\text { Control hepatocytes } \\
\mu \times \mu\end{array}$ & $\begin{array}{c}\text { BCPMP-treated hepatocytes } \\
\mu \times \mu\end{array}$ \\
\hline Microperoxisomes** & $0.21 \pm 0.05 \times 0.18 \pm 0.04$ & $0.23 \pm 0.05 \times 0.18 \pm 0.05$ \\
Normal peroxisomes*** & $0.54 \pm 0.15 \times 0.46 \pm 0.14$ & $0.67 \pm 0.21 \times 0.55 \pm 0.19$ \\
Giant peroxisomes**** & & $1.33 \pm 0.19 \times 1.07 \pm 0.17$ \\
\hline
\end{tabular}

* Calculated from Fig. 5.

** Below $0.29 \mu$ in longitudinal diameter

*** Between $0.30 \mu$ and $0.99 \mu$ in longitudinal diameter

**** Over $1.0 \mu$ in longitudinal diameter 
single limiting membrane (Figs. 1, 2, 3, 5, 7). Fig. 5 and Table 1 show that peroxisomes in control liver were divided into 2 groups; mature normal peroxisomes (over $0.30 \mu$ in diameter) and microperoxisomes (below $0.29 \mu$ in diameter). Microperoxisomes, terminologically proposed by Novikoff and Novikoff (13), were closely related to the rough endoplasmic reticulum, and had rather slightly electron opaque

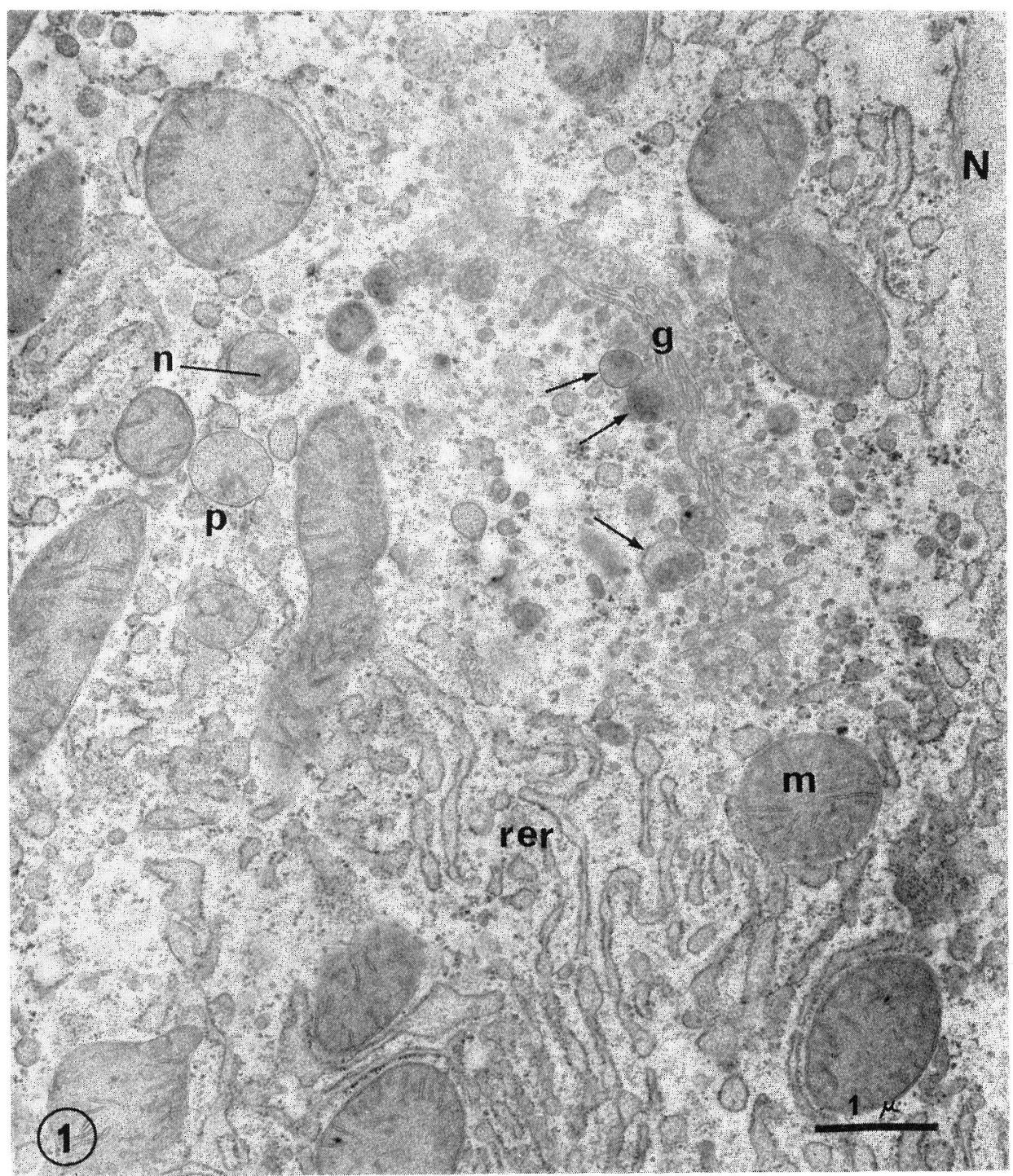

FIG. 1. Normal male DD mouse liver. Mature peroxisomes (p) bearing nucleoids (n) are distrubuted in cytoplasm. Some single membrane-limited vesicles (arrows) are seen in the Golgi area $(\mathrm{g})$, which contain dense materials slightly similar to nucleoids of peroxisomes. $N$, nucleus; $m$, mitochondria; rer, rough endoplasmic reticulum, $\times 15,000$. 


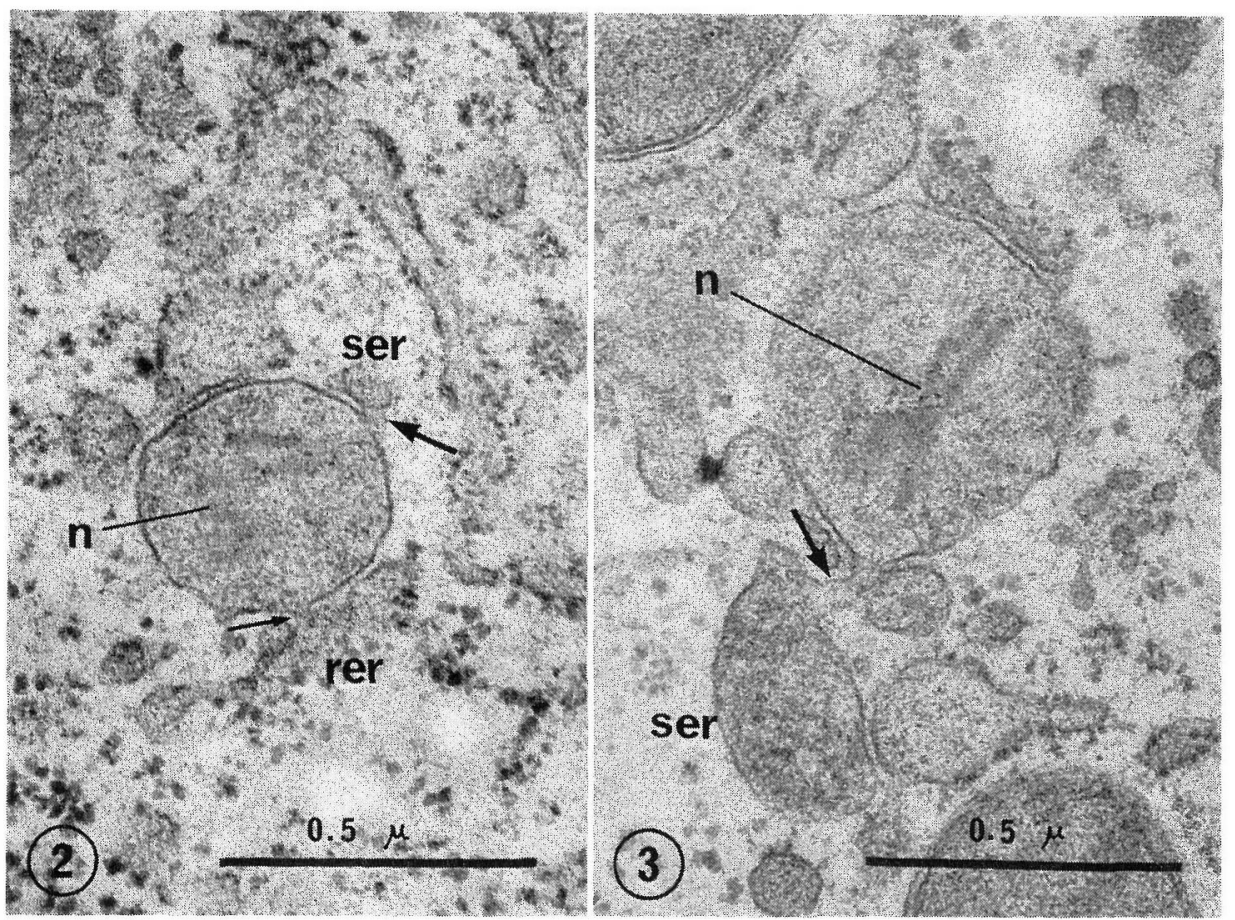

Figs. 2 and 3. Peroxisomes in normal mouse liver. Bold arrows show continuities between peroxisomes and smooth endoplasmic reticulum (ser). Continuity with partially rough endoplasmic reticulum (rer) is also evident (arrow). n, nucleoids. $\times 64,000$.

matrices than normal peroxisomes. Nucleoids were barely found in microperoxisomes. Typical normal peroxisomes in which matrices were homogeneously, somewhat loosely granular contained ill defined nucleoids like complicated strings with highly varied configurations. Continuities between peroxisomes and membranes of smooth or rough endoplasmic reticulum (ER) were much frequently observed (Figs. 2, 3). Furthermore, all peroxisomes, even if the connections were not apparent, were arranged closely to the ER, probably indicating functional relationships between them.

\section{$B C P M P$-treated liver}

Cytoplasms of BCPMP-treated hepatocytes were filled up mainly with mitochondria, smooth and rough ER, Golgi apparatus, background parenchymal proteins, and abnormally enlarged peroxisomes (Fig. 4). Liver weight increased $52 \%$ (Table 2). The size of individual cells increased slightly, and the contents were enriched more than control cells. However, practically no cells in mitosis were observed.

Marked enlargement in size and increase in number of peroxisomes were visualized in all hepatocytes treated with BCPMP for 7 days (Figs. 4, 6, 8, 10). All enlarged peroxisomes were clearly limited by a single membrane. Their general shapes were never extensively spherical but formed irregular unevenness. 


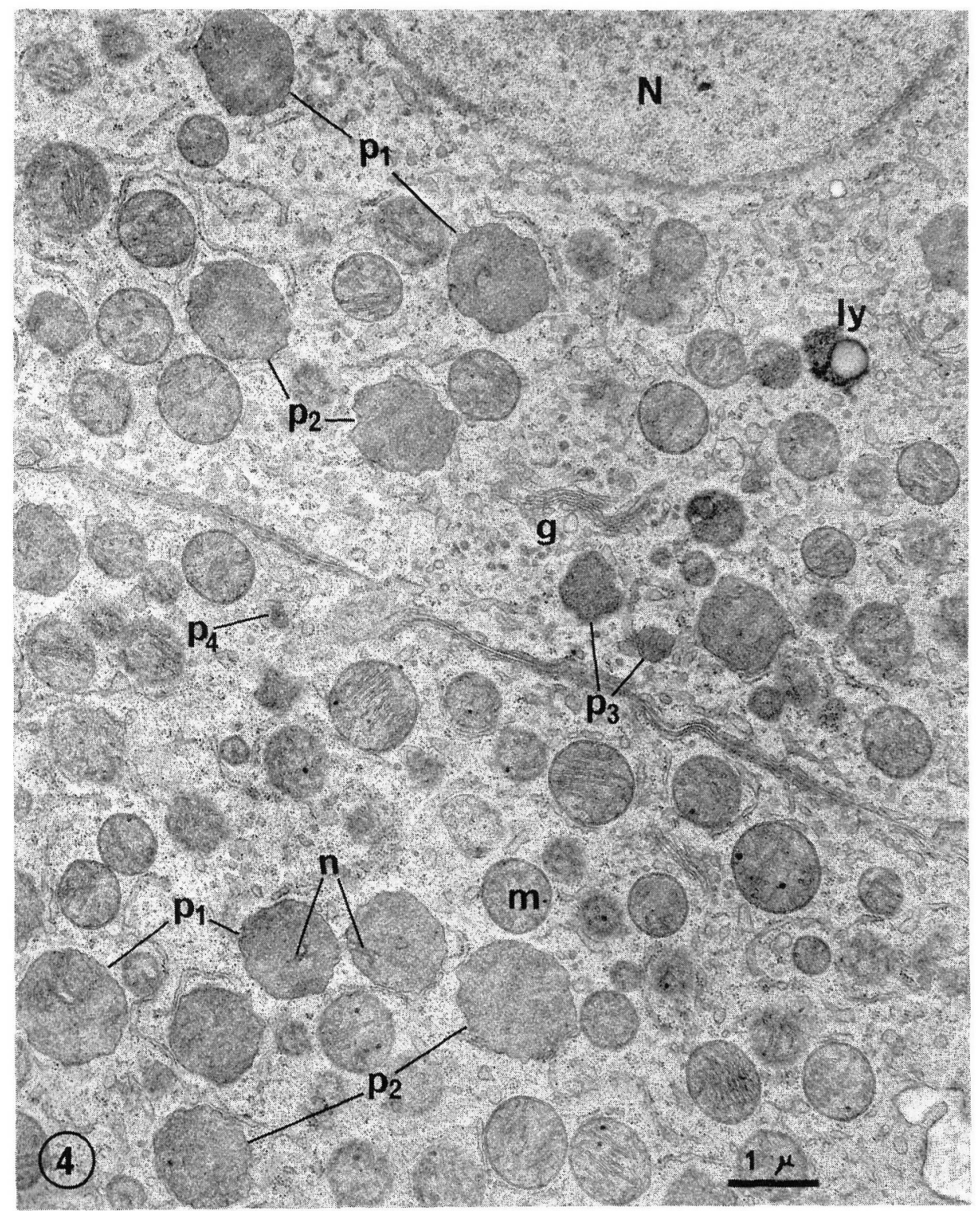

Fig. 4. BCPMP-treated (for 7 days) male mouse liver. Increase in number and size of nucleoid peroxisomes ( $\left.p_{1}\right)$ or just anucleoid peroxisomes $\left(p_{2}\right)$ is remarkable. Irregular normal-sized $\left(\mathrm{p}_{3}\right)$ and micro-sized peroxisomes $\left(\mathrm{p}_{4}\right)$ are seen. $N$, nucleus; n, nucleoids; m, mitochondria; g, Golgi apparatus; ly,lysosome. $\times 11,500$.

Maximum size of the enlarged peroxisomes ("giant peroxisomes") was $1.7 \times 1.5 \mu$ and approximately 2.5 times larger as compared with controls (Figs. 6, 7). Size distribution and number population of peroxisomes are shown in Fig. 5 and Tables 1 and 2. Peroxisomes in BCPMP-treated liver could be divided into 3 groups; microperoxisomes, normal peroxisomes and giant peroxisomes. 
TABLE 2 Effect of BCPMP on liver weight, size of hepatocytes, and number of peroxisomes in male DD mice

\begin{tabular}{c|c|c|c|c}
\hline $\begin{array}{c}\text { Group } \\
\text { (No. of mice) }\end{array}$ & Body weight & $\begin{array}{l}\text { Liver weight } \\
\mathrm{g} / 100 \mathrm{~g} \text { body } \\
\text { weight }\end{array}$ & $\begin{array}{l}\text { Size of hepatocytes } \\
\mu \times \mu\end{array}$ & $\begin{array}{l}\text { No. of } \\
\text { peroxisomes } * * *\end{array}$ \\
\hline $\begin{array}{c}\text { Control (9) } \\
\text { BCPMP-treated } \\
\text { for 7 days (9)* }\end{array}$ & $22.37 \pm 1.79$ & $8.06 \pm 1.48$ & $25.34 \pm 5.05 \times 25.28 \pm 4.85$ & $40.25 \pm 8.40$ \\
\hline
\end{tabular}

* One mouse was dead on the fifth day.

** Mean \pm standard deviation

*** Number in $100 \mu^{2}$-cytoplasmic area of hepatocytes on each 32 micrographs was determined from DAB-stained specimens.

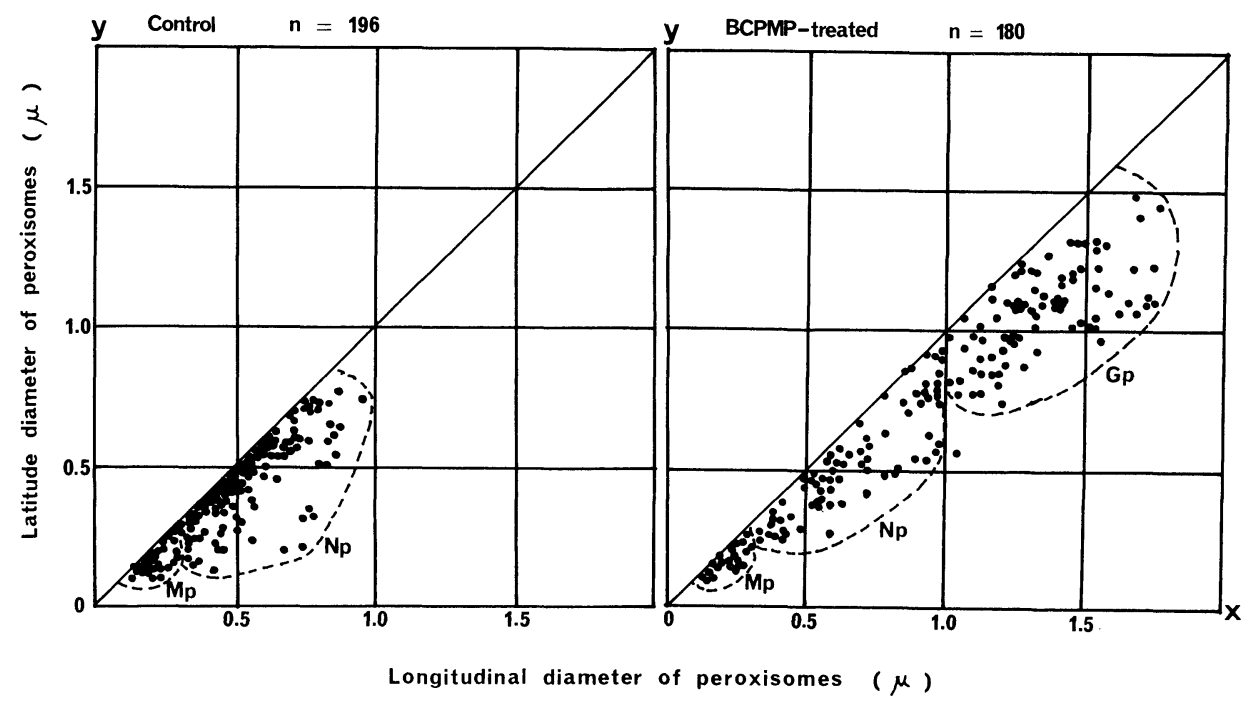

FIG. 5. Size-distribution of peroxisomes. Longitudinal diameter $(x)$ indicates the longest width of peroxisomes, and latitude diameter $(\mathrm{y})$ is vertical to it. Peroxisomes are displayed in 3 groups; mature normal peroxisomes $(\mathrm{Np})$, microperoxisomes $(\mathrm{Mp})(13)$, and giant peroxisomes $(\mathrm{Gp})$.

Giant peroxisomes has several remarkable characteristics. The matrix was enriched by rather loosely granular substances, however, no difference in the density of matrix was visible between control and BCPMP-treated peroxisomes (Figs. 6, 7). The presence of one nucleoid per one peroxisome is evident in many giant peroxisomes, and their conformations were highly varied. No increase in size of nucleoids was observable. Therefore, the ratio of the nucleoid to the matrix was decreased. Although some anucleoid giant peroxisomes were found in the experimentally altered hepatocytes, there is no significant difference in the conformations between peroxisomes with and without nucleoids (Figs. 4, 6).

As additional properties of peroxisomes, these particles were closely associated 


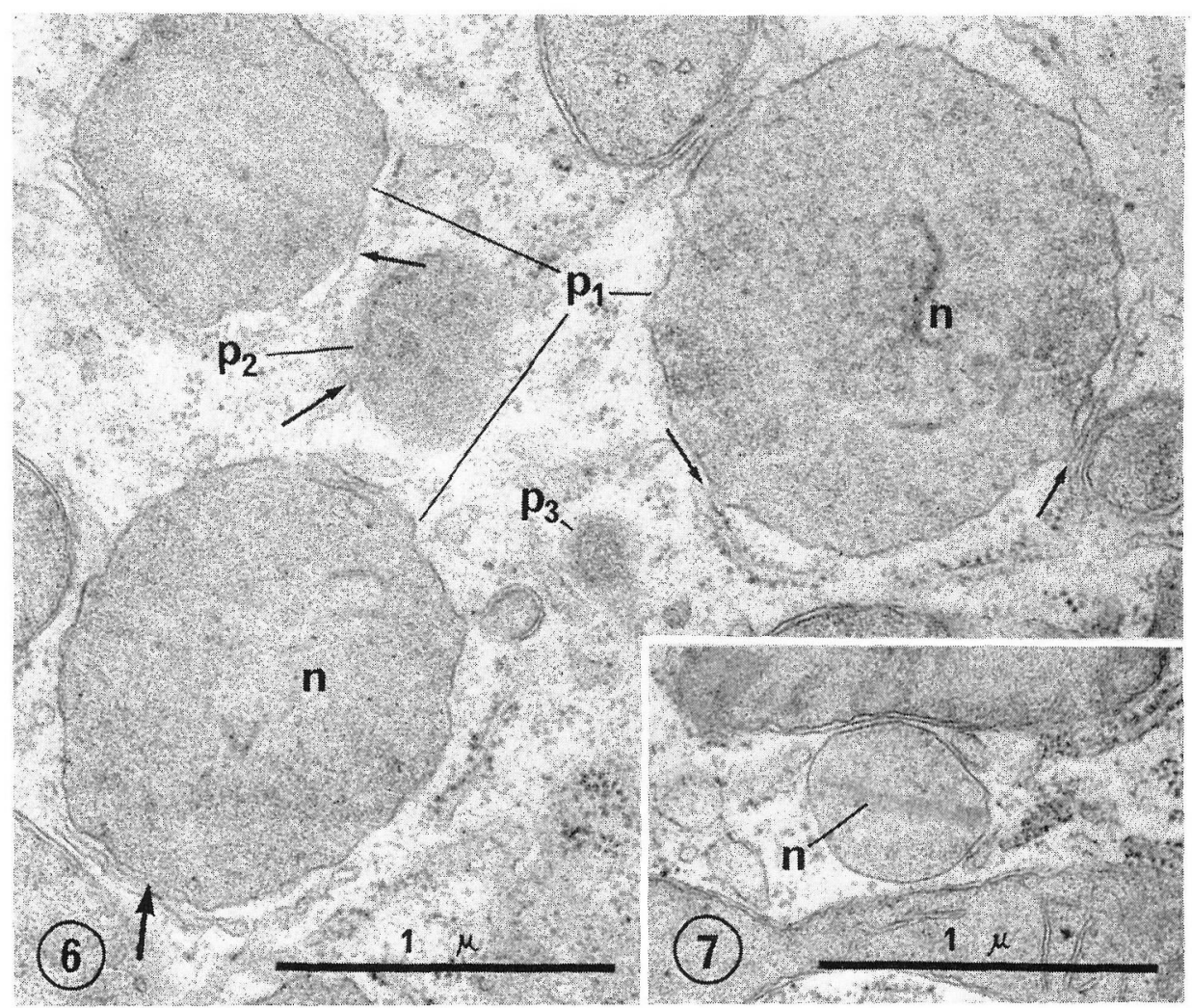

FIG. 6. Typical giant peroxisomes $\left(\mathrm{p}_{1}\right)$ in BCPMP-treated mouse liver. Ciontinuities or close attachments with partially rough endoplasmic reticulum (arrows), and with smooth one (bold arrow) are visible. Electron-dense normal-sized ( $\left.\mathrm{p}_{2}\right)$ and microsized anucleoid peroxisome-like vesicles $\left(\mathrm{p}_{3}\right)$ show invisible limiting membranes. Compare the size of peroxisomes and of nucleoids (n) with Fig. $7 . \quad \times 36,000$.

Frg. 7. The peroxisome in normal mouse liver. $\times 36,000$.

with partially granular ER (Figs. 4, 6). The narrow cisternae of ER frequently, attached with their agranular parts to peroxisomes. Continuities with smooth ER were often encountered (Figs. 6, 8). Normal and microperoxisomes with or without nucleoids were also seen at high rate (Figs. 6, 8, 10). Their shapes were irregular and had slightly electron-dense matrices as compared with giant peroxisomes. The membranc structures of these small peroxisomes were often invisible. Continuities between normal peroxisomes and smooth ER were noticeable (Fig. 8). Occasionally, connection by ER between a giant peroxisome and a normalsized peroxisome was seen (Fig. 8).

By the cytochemical technique the peroxidatic activity of catalase was demonstrated in all peroxisomes (Figs. 9, 10), and was distributed throughout the enlarged matrix of giant peroxisomes. 


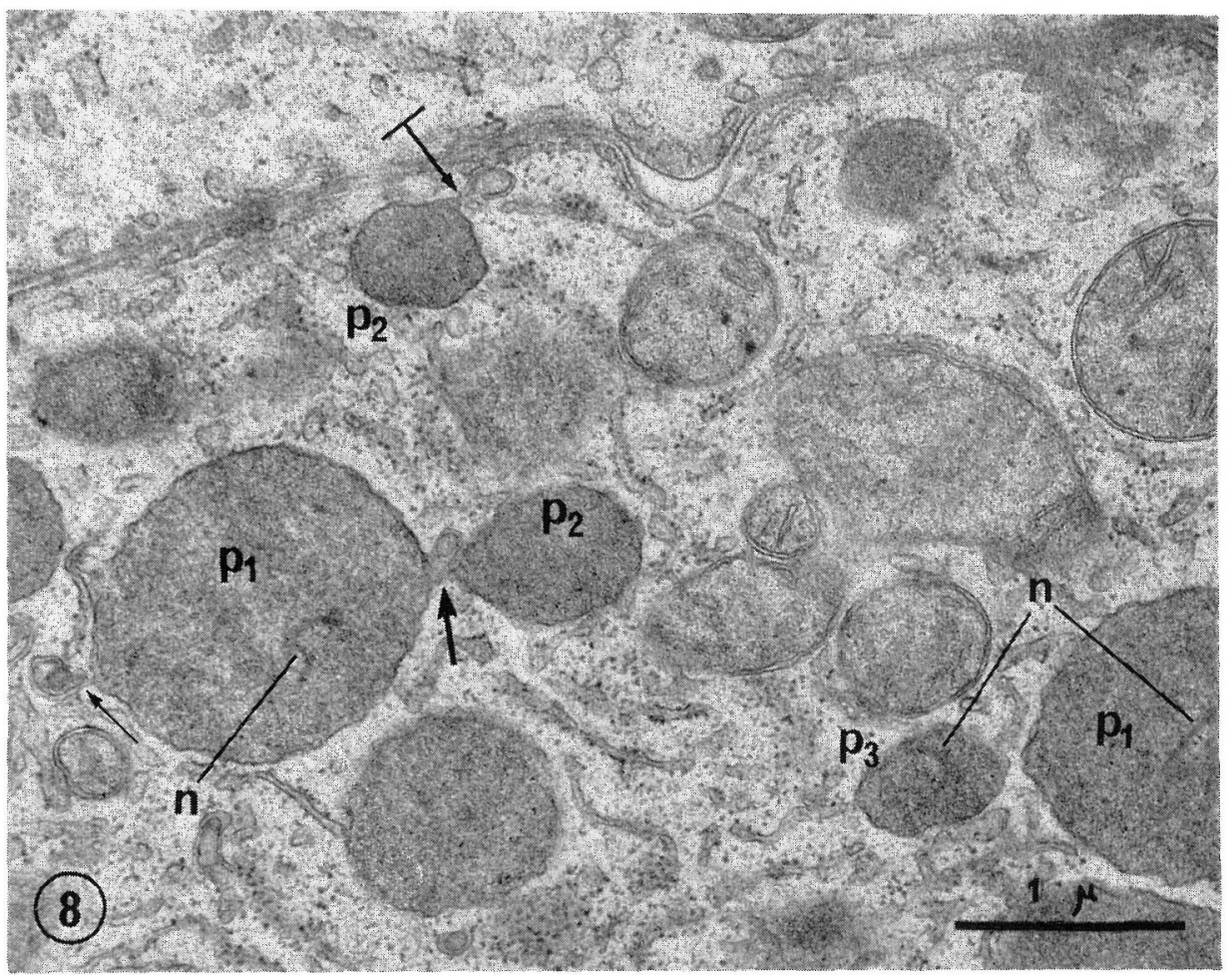

FIG. 8. BCPMP-treated mouse liver. Bold arrow shows an endoplasmic reticular connection between a giant peroxisomes $\left(\mathrm{p}_{1}\right)$ and a normal-sized anucleoid peroxisome $\left(\mathrm{p}_{2}\right)$. This giant peroxisome continues with a hook-shaped smooth endoplasmic reticulum (left arrow), and this feature is identical to that of a normal-sized anucleoid peroxisome $\left(\mathrm{p}_{2}\right)$ indicated by tailed arrow. A normal-sized nucleoid peroxisome $\left(\mathrm{p}_{3}\right)$ is seen. $\mathrm{n}$, nucleoids. $\times 23,600$.

\section{DISGUSSION}

Hess et al. (6) and Svoboda and his co-workers $(17,19,21,23)$ have shown that ethyl- $\alpha$-p-chlorophenoxyisobutyrate (CPIB) induces progressive changes in the rate of hepatic catalase synthesis and in the number of peroxisomes in liver cells. In our present study it was observed that 1,3-propyl-bis(2-p-chlorophenoxy-2-methylpropanoate) (BGPMP), the molecular structure of which is a symmetrically dimer of CPIB, produced giant peroxisomes in the male mouse liver. This megalo-effect seems to be general in DD mouse liver after administration of BCPMP for 7 days in a dose of $1,000 \mathrm{mg} / \mathrm{kg}$ body weight. The enlargment of peroxisomes resulting in the formation of "giant peroxisomes" has never been described precisely, although Stäubli and Hess (20) suggested briefly in their abstract.

The liver weight increased effectivcly, and it seems to be caused by hypertrophy of parenchymal cells. However, the elevation in size of individual cells was not so large as the increase of weight. It is not unlikely, therefore, that the hepatomegaly 

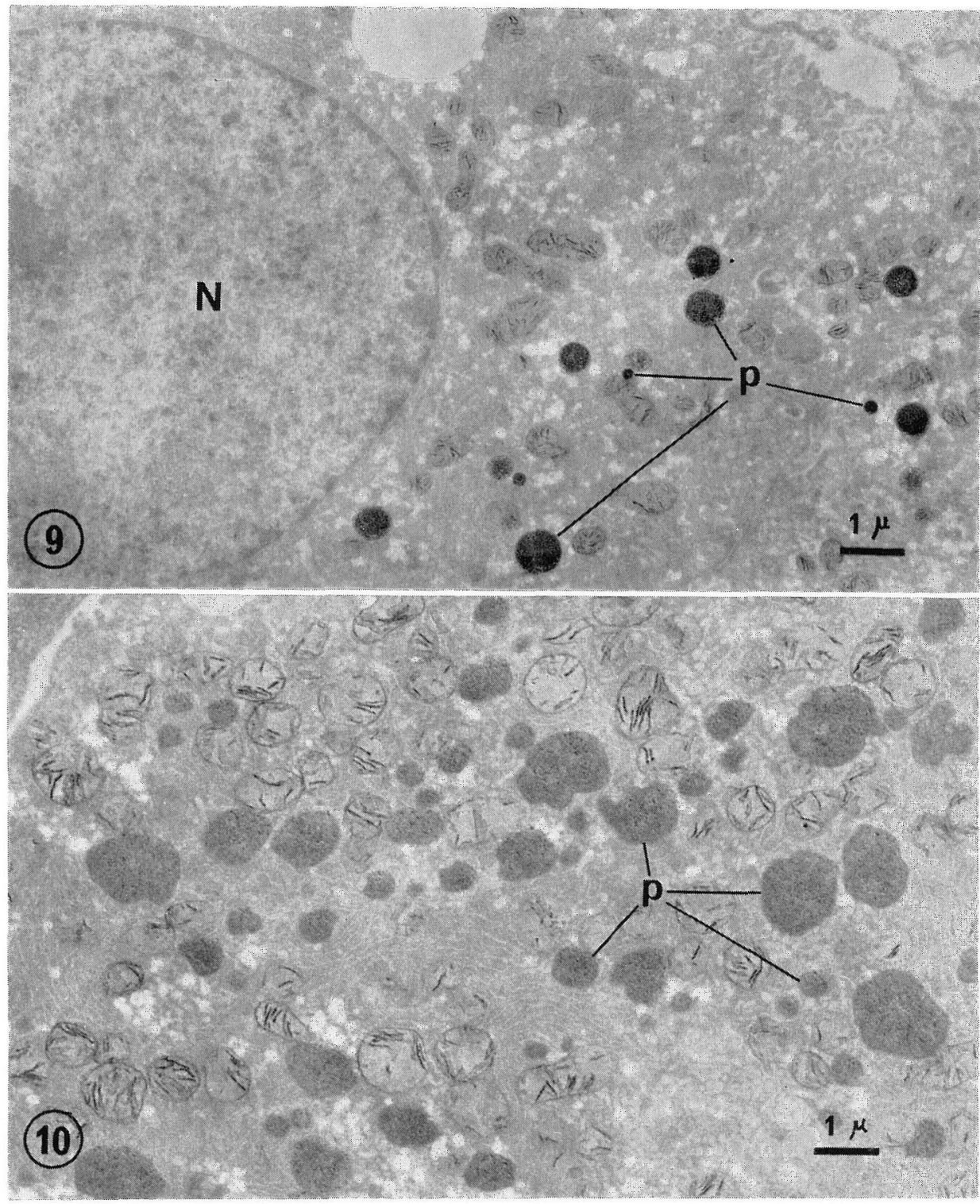

FIG. 9. Peroxidatic activity of peroxisomal catalase in normal mouse liver demonstrated by $\mathrm{DAB}$-method. In mitochondria $\mathrm{DAB}$ products by incidential function of cytochrome $\mathrm{c}$ are seen. $\mathrm{N}$, nucleus; $\mathrm{p}$, peroxisomes. Unstained. $\times 8,200$.

FIG. 10. DAB reaction in BCPMP-treated mouse liver. Increase in number and size of peroxisomes $(p)$ is evident. Unstained. $\times 8,200$.

was resulted by enhanced protein synthesis followed by richness in cytoplasmic contents.

In all normal hepatocytes, 2 types of peroxisomes, that is, mature normal peroxisomes bareing nucleoids, and small-sized microperoxisomes (13) were 
observed. Both of them had continuities with rough or smooth ER, however, the microperoxisomes frequently aboided nucleoids. Therefore, it is difficult to identify the microperoxisomes, if careful observations were not done. The microperoxisomes were slightly electron-denser than the cisternae of smooth ER, and easily demonstrated by DAB-methods.

When mice were affected by BCPMP, abnormally enlarged giant peroxisome group was added to normal and microperoxisomes. However, normal-sized peroxisomes showed irregular shapes and lacked nucleoids, which were not observed in normal peroxisomes in control hepatocytes. These irregularly shaped peroxisomes having no nucleoids might be formed newly from microperoxisomes by accelerated functions. Giant peroxisomes had matrix enriched with peroxisomal proteins, the greater part of which was catalase as suggested by cytochemical data (Fig. 10). In almost all of giant peroxisomes, the limiting membranes were associated or connected with rough or smooth ER. The relationships between peroxisomes and ER were also observed in control hepatocytes (Figs. 3, 4), and is closely similar to the findings by Svoboda and his co-workers $(18,19,21,23)$. There have been many studies which demonstrated prominent continuities between $\mathrm{ER}$ and peroxisomes (microbodies) suggesting the origin of the particles in normal rat liver (14), in fetal mouse liver (2,3), in developing liver of chick (4), in fetal rat liver (24), in fat body of an insect (9), in inner adrenocortical cells of guinea pigs (1) or in plants $(5,25)$, and it is conceivable that the synthesis of some peroxisomal matrix proteins, probably mainly catalase, was stimulated in ER and subsequently newly formed proteins were transfered to pre-existed peroxisomes. It is difficult to consider that proteins were synthesized within peroxisomes.

Legg and Wood (8) suggested that peroxisome proliferation seen in the early period of CPIB administration was a process of flagmentation or budding from pre-existing peroxisomes, without any participation of smooth ER. Although their idea should be attended to, we could not find no profiles which are suggesting direct budding. A peroxisome-to-peroxisome connection is visible in Fig. 8 in the present study. By further careful observation the presence of a small loop-shaped smooth ER can be seen in the intermediate connection. Accordingly it may be considered that this profile suggests two-direction transport of newly synthesized proteins from a single ER resulting in two peroxisomes, mutual transport of peroxisomal proteins between two peroxisomes through ER channel (indirect budding), or fusion. Reddy and Svoboda $(18,19)$ found similar profiles in CPIB-treated animals, and concluded that peroxisomal proteins constitute a common circular pool, and peroxisomes do not exist as individual entities.

In the largest giant peroxisomes, both nucleoid and anucleoid peroxisomes were observable in all hepatocytes affected by BCPMP. There are no structural differences between them except the nucleoids. It cannot be concluded that anucleoid peroxisomes are essential for the hepatocytes treated with BCPMP for 7 days, since anucleoidal features can easily be obtained from nucleoid peroxisomes by accidental sectioning passing through the matrix only.

The further detailed experiments on the progression and regression of giant peroxisomes in relation to the pharmacological effect of BCPMP are being in progress. 


\section{REFERENCES}

1. Black, V.H. and Bogart, B. I.: Peroxisomes in inner adrenocortical cells of fetal and guinea pigs. J. Cell Biol. 57: 345, 1973.

2. Essner, E.: Endoplasmic reticulum and the origin of microbodies in fetal mouse liver. Lab. Invest. 17: 71, 1967.

3. Essner, E.: Localization of peroxidase activity in microbodies of fetal mouse liver. J. Histochem. Cytochem. 17: 454, 1969.

4. Essner, E.: Observations on hepatic and renal peroxisomes (microbodies) in the developing chick. J. Histochem. Cytochem. 18; 80, 1970.

5. Frederick, S. E., Newcomb, E. H., Vigil, E. and Wergin, W. P.: Fine-structural characterization of plant microbodies. Planta (Berl.) 81; 229, 1968.

6. Hess, R., Stäubli, W. and Riess, W.: Nature of the hepatomegalic effect produced by ethylchlorophenoxy-isobutyrate in the rat. Nature 208; 856, 1965.

7. Hirai, K-I.: Light microscopic study of the peroxidatic activity of catalase in foraldehyde-fixed rat liver. J. Histochem. Cytochem. 17; 585, 1969.

8. Legg, P. G. and Wood, R. L.: New observations on microbodies: A cytochemical study on CPIB-treated rat liver. J. Cell Biol. 45; 118, 1970.

9. Locke, M. and McMahon, J. T.: The origin and fate of microbodies in the fat body of an insect. J. Cell Biol. 48; 61, 1971.

10. Nakanishi, M., Imamura, H., Matsui, E. and Kato, Y.: Effect of 1,3-propanediol bis( $\alpha$-pchlorophenoxyisobutyrate) (CLY-503) on cholesterol biosynthesis in the rat. Yakugaku Zasshi (in Japanese) 90;267, 1970.

11. Nakainsh, M., Kobayashi, T., Okada, T. and Gotoh, K.: Studies on anti-atherosclerotic agents: II. Experimental studies of 1,3-propanediol bis(2-p-chlorophenoxyisobutyrate) (CLY-503) for anti-atherosclerotic agents. Yakugaku Zasshi (in Japanese) 90; 926, 1970.

12. Novikoff, A. B. and Goldfischer, S.: Visualization of microbodies for light and electron microscopy. J. Histochem. Cytochem. 16; 503, 1968.

13. Novikoff, P. M. and Novikoff, A. B.: Peroxisomes in absorptive cells of mammalian small intestine. J. Cell Biol. 53; 532, 1972.

14. Novikoff, A. B. and Shin, W. Y.: The endoplasmic reticulum in the Golgi zone and its relations to microbodies: Golgi apparatus and autophagic vacuoles in rat liver cells. J. Microsc. 3; 187, 1964.

15. Reddy, J., Bunyaratvej, S. and Svoboda, D.: Microbodies in experimentally altered cells: IV. Acatalasemic $\left(\mathrm{Cs}^{\mathrm{b}}\right)$ mice treated with CPIB. J. Cell Biol. 42; 587, 1969.

16. Reddy, J., Bunyaratvej, S. and Svoboda, D.: Microbodies in experimentally altered cells: V. Histochemical and cytochemical studies on the livers of rats and acatalasemic $\left(\mathrm{Cs}^{\mathrm{b}}\right)$ mice treated with CPIB. Am. J. Pathol. 56; 351, 1969.

17. Reddy, J., Chiga, M., Bunyaratvej, S. and Svoboda, D.: Microbodies in experimentally altered cells: VII. CPIB-induced hepatic microbody proliferation in the absence of significant catalase synthesis. J. Cell Biol. 44;226, 1970.

18. Reddy, J. and Svoboda, D.: Microbodies in experimentally altered cells: VIII. Continuities between microbodies and their possible biologic significance. Lab. Invest. 25; 74, 1971.

19. Reddy, J. and Svoboda, D.: Further evidence to suggest that microbodies do not exist as individual entities. Am. J. Pathol. 70; 421, 1973.

20. Stäubli, W. and Hess, R.: Quantitative aspects of hepatomegaly induced by ethyl chlorophenoxyisobutyrate (CPIB). In the Electron Microscopy, ed. by R. Uyeda, Maruzen Co., Ltd., Tokyo, 1966, Vol. II, p. 625.

21. Svoboda, D. J. and Azarnoff, D. L.: Response of heptatic microbodies to a hypolipidemic agent, ethyl chlorophenoxyisobutyrate (CPIB). J. Cell Biol. 30; 442, 1966.

22. Svoboda, D., Azarnoff, D. and Reddy, J.: Microbodies in experimentally altered cells: II. The relationship of microbody proliferation to endocrine glands. J. Cell Biol. 40; 734, 1969. 
23. Svoboda, D., Grady, H. and Azarnoff, D.: Microbodies in experimentally altered cells. $J$. Cell Biol. 35; 127, 1967.

24. Tsukada, H., Mochizuki, Y. and Konishi, T.: Morphogenesis and development of microbodies of hepatocytes of rats during pre- and postnatal growth. J. Cell Biol. 37; 231, 1968.

25. Vigil, E. L.: Cytochemical and developmental changes in microbodies (glyoxysomes) and related organelles of castor bean endosperm. J. Cell Biol. 46; 435, 1970. 